\title{
The Relationship of Preterm Infant-Mother Attachment to Stranger Sociability at 3 Years
}

\author{
James W. Plunkett, Tovah Klein, and Samuel J. Meisels \\ University of Michigan
}

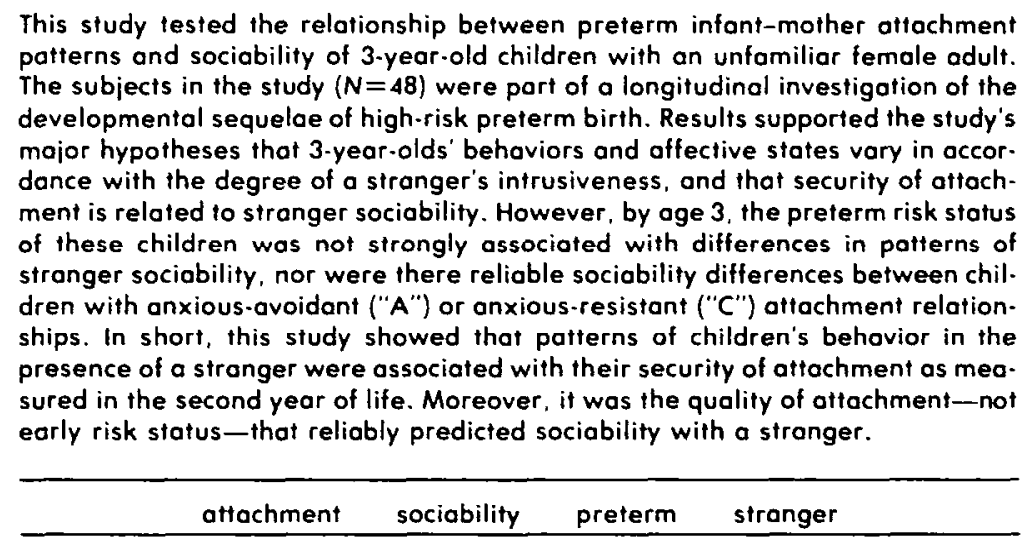

Children's interactions with strangers, particularly in infancy, have captured the attention of researchers for decades. Spitz (1965) attempted to link "stranger anxiety" to the infant's feelings of maternal loss; Stevenson and Lamb (1979) found strong relationships between stranger sociability and measures of the home environment and of cognitive competence; Thompson and Lamb (1982) discovered relationships between sociability, measures of temperament, and family social stability among older infants (i.e., 191/2 months); and Frodi (1983) reported that at 1 year both full-term and healthy preterm infants who were securely attached were more sociable than anxiously attached infants when concurrently assessed in a stranger-sociability paradigm.

This investigation was supported in part by a faculty research award from the Rackham School of Graduate Studies of The University of Michigan and a grant from the March of Dimes Birth Defects Foundation. It is based on a Senior Honors Thesis in Psychology completed by the second author at the University of Michigan and was presented at the meeting of the Society for Research in Child Development, Baltimore, MD, April, 1987. Grateful acknowledgment is made to Dietrich Roloff, Patricia Pasick, Gilbert Stiefel, Karen Mikus, and Ellen Wolock for their assistance in this project; to L. Alan Sroufe and Wayne Duncan for their assistance in the assessment of infant attachment; to Tom TenHave for his invaluable methodological consultation; to David Cross for comments on an earlier draft; and to the parents and children who participated in the study.

Correspondence and requests for reprints should be sent to James W. Plunkett, University Center for the Child and Family, University of Michigan, 1007 E. Huron, Ann Arbor, Ml 48109. 
The purpose of these studies has been to understand individual differences in infant sociability and in the way that infants behave in social situations. However, few investigations have studied stranger sociability among preschoolage children or have examined the predictive relationship between early measures of infant socioemotional development and sociability assessed at a later point. One investigation of social behavior of 3-year-olds, by Clarke-Stewart (1978), provided a descriptive baseline of the behavior of 3-year-olds in relationship to the gradual intrusion of an unfamiliar adult. The study used a laboratory procedure in which the mother and child were together when a stranger entered. In this procedure, the stranger approached the child, gradually increasing her intrusiveness. Clarke-Stewart found clearly different patterns in the children's behavior, reflecting the degree of intrusiveness of the stranger's behavior.

In order to study factors related to the development of individual differences in stranger-sociability behavior at age 3 , the present investigation focuses on two important sources of individual differences in early socioemotional development: high-risk preterm birth and the quality of the mother-infant attachment relationship. Observations of the preterm infant-mother relationship during the first year of life have demonstrated that this dyadic relationship is at substantially increased risk for interactional problems that could contribute to less optimal socioemotional development (Brachfeld, Goldberg, \& Sloman, 1980; Crawford, 1982; Crnic, Greenberg, Ragozin, Robinson, \& Basham, 1983; DiVitto \& Goldberg, 1979; Field, 1977; Minde, Whitelaw, Brown, \& Fitzhardinge, 1983). However, while heightened socioemotional risk in the first few months of life has been extensively studied, there has been little empirical observation of socioemotional development beyond the first year of life (Meisels \& Plunkett, in press).

One exception to this has been research regarding preterm infant-mother attachment relationships and the preterm infant's capacity for affect regulation, resiliency, and engagement of the environment between 12 and 18 months of age. To date, however, the results of this research have been inconclusive, with some investigators (Plunkett, Meisels, Stiefel, Pasick, \& Roloff, 1986; Stiefel, Plunkett, \& Meisels, 1987) reporting an association of preterm risk status with different patterns of attachment and capacities for affect regulation, and others (Frodi \& Thompson, 1985; Goldberg, Perrotta, Minde, \& Corter, 1986) failing to find such an association. Moreover, there have been no prospective studies of the relationshp of preterm risk status to preschool children's sociability with unfamiliar adults.

More extensive information is available among normative groups concerning the role of the mother-child attachment relationshp as a precursor to the child's socioemotional development (Matas, Arend, \& Sroufe, 1978; Sroufe, 1983; Waters \& Deane, 1985). Attachment has been shown to be an important predictor of the preschool child's emerging social competence, self-confidence, and resiliency in a number of different situations and settings (Bretherton \& Waters, 1985). Moreover, Lutkenhaus, Grossman, and Grossman (1985) in- 
vestigated attachment as a predictor of sociability among German 3-year-olds. They found that children who were securely attached interacted more quickly with the stranger than those who were insecurely attached.

The present study seeks to determine if preterm risk status and the interactive experiences that result in the establishment of a secure attachment are in fact associated with differences in how effectively children interact with and respond to unfamiliar adults later in childhood. The focus of the present study is on the patterns of reactions of 3-year-olds in the presence of their mothers to the gradual intrusion of a stranger during a structured laboratory situation. All of the children participating in the study were previously studied in the Ainsworth Strange Situation (Ainsworth, Blehar, Waters, \& Wall, 1978) during their second year of life as part of a longitudinal investigation of the sequelae of high-risk preterm birth. All of the subjects were born prematurely-some at high risk, due to respiratory illness and extended hospitalization, and some at low risk.

The study is guided by four hypotheses. The first hypothesis concerns how 3-year-olds as a group will react to the approach, intrusiveness, and withdrawal of a strange adult. Adapting a procedure from Clarke-Stewart (1978), it was predicted the children's behaviors and affective states would vary in accordance with the degree of the stranger's intrusiveness. Specifically, because the procedure that was used followed the format of low intrusion-high intrusion-low intrusion, it was predicted that a curvilinear profile reflecting this low-high-low pattern would best fit the pattern of children's responses across the episodes of the stranger-sociability paradigm.

The other three hypotheses focus on the specific predictive relationships of preterm risk status and attachment to stranger sociability. It was hypothesized that sick, high-risk preterm infants would be less sociable when approached by a stranger than would healthy, low-risk infants. Specifically, it was expected that their behavior would reflect more stress, less positive affect, less toy play, less sociability with a strange adult, and closer proximity to and more interaction with the mother. Moreover, it was predicted that secure attachments would be associated with more sociable behavior than insecure attachments. Finally, it was hypothesized that infants who had " $C$ " (anxious-resistant) attachment relationships would be more likely to display a pattern of low sociability behaviors than those who had " $A$ " (anxious-avoidant) attachment relationships.

\section{METHOD}

\section{Subjects}

The subjects in this study $(N=48)$ were part of a longitudinal investigation of the developmental sequelae of high-risk preterm birth. All of the subjects weighed less than $2501 \mathrm{gms}$ at birth and had gestational ages of less than 37 weeks. The infants were born between September 1980 and August 1982. They 
were identified from consecutive admissions records of a large midwestern university hospital.

Two groups of infants were studied: high-risk preterms $(n=30)$ and low-risk preterms $(n=18)$ (see Table 1). The high-risk children had moderate to severe respiratory illness (as determined by radiographs) and an initial hospitalization of more than 1 month. The low-risk group was free of respiratory illness and was hospitalized for less than 1 month. The perinatal and demographic characteristics of both groups are presented in Table 1 . The groups were balanced by sex, parity, and socioeconomic status (SES).

\section{Assessment Points}

The infants were studied in both the second and fourth years of life. Assessment took place at either 12 or 18 months Time Post-Hospital Discharge (TPD) and at 36 months TPD. This time point was selected, rather than corrected chronological age, so that all subjects would have comparable lengths of time to experience their home environment.

In studies which examine factors closely associated with home-based caregiving experience, it is important to equate groups on length of time at home in order to assure equal opportunity among groups for establishing this relationship. If, in contrast, groups are equated on corrected gestational age, less optimal relationships may be found among sicker, higher-risk infants because these infants will have had less time at home due to longer initial hospitalization. Because it is impossible to equate groups on both corrected age and TPD, this study equated groups by TPD as a more conservative approach that was less likely to bias the results in the direction predicted in the hypotheses.

Infants were initially studied at either 12 or 18 months TPD in order to investigate the relationship between chronological age and attachment. In subsequent analyses, no Age main effects and no Age $\times$ Group interactions were observed (see Meisels, Cross, \& Plunkett, 1987; Plunkett et al., 1986). Hence, for the purpose of data analysis, subjects were combined across the 12- and 18month age groups.

TABLE 1

Perinatal and Demographic Characteristics

\begin{tabular}{llccc}
\hline $\begin{array}{l}\text { Perinotal/Demographic } \\
\text { Characteristics }\end{array}$ & $\begin{array}{c}\text { Sick PT } \\
(n=30)\end{array}$ & $\begin{array}{c}\text { Healthy PT } \\
(n=18)\end{array}$ & $\begin{array}{c}\text { Significance } \\
\text { Tests }\end{array}$ & $p<$ \\
\hline Birth weight (gms) & $\begin{array}{l}\text { M: } 1399 \\
\text { SD: }(389)\end{array}$ & $\begin{array}{l}2143 \\
(245)\end{array}$ & $F=52.9$ & .0001 \\
Gestational age (weeks) & $M: 30.6$ & 33.8 & $F=22.7$ & .0001 \\
Hospitalization (days) & SD: $(2.5)$ & $(1.9)$ & $F=52.4$ & .0001 \\
Sex: male (\%) & M: 58.2 & 10.9 & & n.s. \\
SES: low (\%) & SD: $(27.1)$ & $(6.6)$ & 67 & n.s. \\
Parity: primiparous (\%) & 50 & 33 & $x^{2}=0.26$ & n.s. \\
\hline
\end{tabular}

Note. $P T=$ preterm; $d$ : F-tests $=1,46 ; x^{2}=1$. 


\section{Sample Size and Attrition}

The original study population consisted of 62 preterm infants, of whom 56 were studied in the Strange Situation. This report focuses on 48 of these subjects. The 48 subjects were derived from a sample of 53 infants who returned for assessment at 36 months TPD. Thus, the attrition rate for the study as a whole was $14.5 \%$.

All 53 subjects were coded in the stranger-sociability procedure. However, data from four of the children could not be used because there were no attachment classifications for them. These infants were considered to be too developmentally immature to be classified at the time they were assessed in the Ainsworth Strange Situation. The fifth child whose data could not be used was excluded because his father was the primary caregiver; all of the other children in the study were assessed with their mothers as their primary caregiver. There were no significant group differences in sex, SES, birth weight, gestational age, or hospital stay when this sample was compared with the original sample that was studied in the second year of life.

\section{Attachment Procedure and Coding}

In their second year, infants were assessed with their primary caregivers in the Ainsworth Strange Situation procedure (Ainsworth et al., 1978). This is a standardized laboratory situation that is widely used for the assessment of quality of the infant-caregiver attachment relationship. It consists of seven 3-min episodes that allow the observer to identify how the infant copes with brief separations from and reunions with primary attachment figures. The complete procedure was followed except in those instances where extreme infant distress required that a separation episode be curtailed. All procedures were videotaped for later coding.

Attachment classifications of the subjects were assigned according to the standard criteria (Ainsworth et al., 1978) for Anxious-Avoidant (A), Secure (B), and Anxious-Resistant (C) attachment. A senior investigator (L. Alan Sroufe) and a rater, trained by Dr. Sroufe, established .88 exact agreement on the nominal A-B-C classifications based on 32 independently coded tapes. The raters were blind to the risk status of the subjects and the hypotheses of the study. (See Plunkett et al., 1986, for a report of the attachment relationships of this sample.)

\section{Stranger-Sociability Procedure and Coding}

At the 36-month assessment, the mother and child returned to a moderate-sized, sparsely furnished playroom with attractive toys. After an initial 5-min freeplay period, the stranger-sociability procedure was conducted. This procedure, adapted from Clarke-Stewart (1978), was designed to provide a structured situation for observing how young children in the presence of their mothers respond to the graduated overtures and approach of a friendly adult. The mothers were instructed to sit quietly but respond naturally to their child's questions, interactions, and requests. 
The procedure consisted of seven episodes lasting a total of $81 / 2 \mathrm{~min}$ (see Table 2). Episode 1 (Prior) consisted of the final $30 \mathrm{~s}$ of a free-play situation that preceded the sociability procedure, providing baseline data on child play and behavior. In Episode 2 (Enters), a female adult unfamiliar to the child entered the room, at first ignoring the child $(1 \mathrm{~min})$ and then looking at the child in a neutral manner $(1 \mathrm{~min})$. In Episode 3 (Elicits), the stranger smiled and greeted the child $(30 \mathrm{~s})$ and then played with a toy in an effort to elicit the child's interest. In Episode 4 (Approach), the stranger invited the child to approach and play ( $1 \mathrm{~min}$ ) and then moved towards the child while continuing the invitation to play if the child had not approached the stranger $(1 \mathrm{~min})$. In Episode 5 (Intrude), the stranger engaged in a physical tickling game which required her to make contact with the child $(1 \mathrm{~min})$. This intrusion was followed by Episode 6 (Retreat) in which the stranger retreated and then left $(1 \mathrm{~min})$. In the final episode (Exit), the mother and child were alone once again ( $30 \mathrm{~s})$.

Six dimensions of child behavior were identified and operationalized as 7-point scales. Each scale point was clearly defined and described.' ${ }^{1}$ The six scales are as follows:

1. Toy and Imaginary Play: The extent to which a child is engaged in toy and/or imaginary play. $(1=$ No play; $7=$ Active play without distraction. $)$

2. Interaction with Mother: The amount of interaction directed toward the mother through play, verbalization, eye contact, facial expression, and/or physical contact. ( $1=$ No interaction; $7=$ Exclusive interaction with mother with no attention to stranger.)

3. Interaction with Stranger: Quality of the interaction with the stranger, ranging from negative (e.g., upset, unfriendly, avoidant) to positive (e.g., approaches stranger, laughs, eagerly plays with stranger $).(1=$ Strong negative reaction to stranger; $7=$ Positive, outgoing, enthusiastic response to stranger.)

4. Affect: Quality of the child's affect, ranging from negative (e.g., cry) to positive (e.g., smile and laugh). ( $1=$ Crying predominates; $7=$ Smiling/ laughter through episode.)

5. Proximity to Mother and Stranger: Measure of where the child is in relationship to both the mother and the stranger. $(1=$ Sitting in the mother's lap; 7 = Physical contact with stranger for at least part of the episode.)

6. Stress: Overall rating of how relaxed or stressed the child appears to be as revealed in child's facial expressions, responses to mother and stranger, toy play, and/or body movement. $(1=$ Relaxed and warm with mother and stranger; $7=$ Upset and unable to calm down.)

The entire procedure was divided into 10 coding periods ( 30 or $60 \mathrm{~s}$ ) as shown in Table 1. This assured that coding periods corresponded to shifts in stranger behavior, and that no scoring period lasted more than $60 \mathrm{~s}$. All six dimensions

' This measure is available upon request from the first author. 
TABLE 2

Description of Stranger-Sociability Procedure

\begin{tabular}{llr}
\hline Episode & Stranger's Mode of Behavior & Duration \\
\hline 1. Prior & Mother and child alone & $30 \mathrm{~s}$ \\
2. Enter & Enters, ignores child: & $1 \mathrm{~min}$ \\
& looks neutrally at child & $1 \mathrm{~min}$ \\
3. Elicit & Smiles and greets: & $30 \mathrm{~s}$ \\
& plays with toy & $1 \mathrm{~min}$ \\
4. Approach & Invites child to play; & $1 \mathrm{~min}$ \\
& invites (continued) & $1 \mathrm{~min}$ \\
5. Intrude & Plays physical game & $1 \mathrm{~min}$ \\
6. Retreat & Retreats; leaves & $1 \mathrm{~min}$ \\
7. Exit & Mother and child alone & $30 \mathrm{~s}$ \\
\hline
\end{tabular}

were scored during each scoring period with one exception: Interaction with stranger could not be scored in Episodes 1 and 7 when the stranger was not present. In Episodes 2 through 4, the mean of the scores for the two scoring periods was taken as the overall score for the episode.

Significant interscale correlations, $p<.01$, for the overall means were obtained $(M r=.58$; range $=.38-.82)$. Although the scales appear to tap a general quality of sociability, they provided nonredundant information as well. In consequence, all six scales were used in the analyses, and MANOVA statistics were utilized in order to account for the redundancy of the measures. Table 3 displays the correlations among the scales.

\section{Reliability}

Two coders blind to risk status and attachment classifications of the children scored the tapes. One coder scored all 48 children while the second scored 23 randomly selected tapes to establish interrater reliability. Because this research focused on the pattern of behavior across episodes, reliability was calculated by coding episodes, resulting in the calculations of 58 reliabilities. Interrater reliability was very high; the median Pearson correlation coefficient by episode was .95 with only four correlations falling below .80 .

TABLE 3

Stranger-Sociability Scales: Correlations

\begin{tabular}{lccccc}
\hline Scales & Toy Play & $\begin{array}{c}\text { Mother } \\
\text { Interaction }\end{array}$ & $\begin{array}{c}\text { Stranger } \\
\text { Interaction }\end{array}$ & Affect & Proximity \\
\hline Mother Interaction & -.57 & - & & & \\
Stranger Interaction & .38 & -.43 & - & & \\
Affect & .59 & -.39 & .49 & & \\
Proximity & .55 & -.81 & .61 & .39 & - \\
Stress & -.82 & .63 & -.63 & -.79 & -.63 \\
\hline
\end{tabular}

Note. $N=48 ; p<.01$. 


\section{RESULTS}

Preterm Risk Status and Attachment

An earlier report presented the association of preterm risk status with attachment for the sample of 56 preterm infants (Plunkett et al., 1986). The results for this reduced sample of 48 are not significantly different from the original report: High-risk infants differed from low-risk infants in the type of insecure attachment relationship (high-risk $=10 \% \mathrm{~A}, 37 \% \mathrm{C}$; low-risk $=28 \% \mathrm{~A}, 5 \% \mathrm{C}$; $\left.\chi^{2}(2)=7.80, p<.02\right)$. However, the two preterm groups did not reliably differ in proportions of secure attachment relationships (high-risk $=53 \% \mathrm{~B}$; low-risk $=$ $67 \% \mathrm{~B})$.

\section{Pattern of Responses During the Stranger-Sociability Procedure}

The stranger-sociability procedure was designed to show that 3-year-olds' behavior and affect state would vary in accordance with the pattern of the stranger's approach and intrusion into their personal space. It was hypothesized, therefore, that the profile of the six dimensions of behaviors and affect would be curvilinear, reflecting the low-high-low intrusion structure of the situation. To test this hypothesis, one-way repeated-measure ANOVAs were performed on the six scales for the groups as a whole, and the fit of a quadratic (i.e., curvilinear) profile was tested. The quadratic profile was highly significant on all but the Affect scale: Toy, $F(4,180)=34.80, p<.0001$; Mother, $F(4,180)=44.30$, $p<.0001$; Stranger, $F(4,180)=41.40, p<.0001$; Proximity, $F(4,180)=52.40$, $p<.0001$; Stress, $F(4,180)=263.50, p<.0001$; Affect, $F(4,180)=0.48$, n.s. Figure 1 displays the curvilinear pattern of these scales. It is apparent that Stress, Toy Play, Proximity, and Mother Interaction follow very similar patterns. The figure shows that as the stranger increased her proximity to the child (Episode 5), the child became increasingly stressed and less involved in playing. In addition, the child's interactions with mother decreased and proximity to the stranger increased as the child's attention became more focused on the playful overtures of the stranger. In contrast, as the stranger withdrew (Episode 6), the child relaxed, reengaged in toy play, and increased the interaction with mother.

A somewhat different pattern was revealed for the Stranger Interaction and Affect dimensions that are shown in Figure 1. A highly significant curvilinear pattern can be observed for the Stranger Interaction scale, but it peaked in Episode 4 (Approach) instead of Episode 5 (Intrude). The children showed the greatest interaction with and interest in the stranger during the Approach episode when the stranger moved close to them. However, as soon as the stranger made physical contact, the children withdrew and did not renew their interest when the stranger retreated.

Figure 1 also shows that Affect is the only profile that is not curvilinear. There was little variability in children's affect across the seven episodes; they appeared to be affectively neutral to mildly positive throughout. The only appearance of increased positive affect occurred when the stranger made a distal 


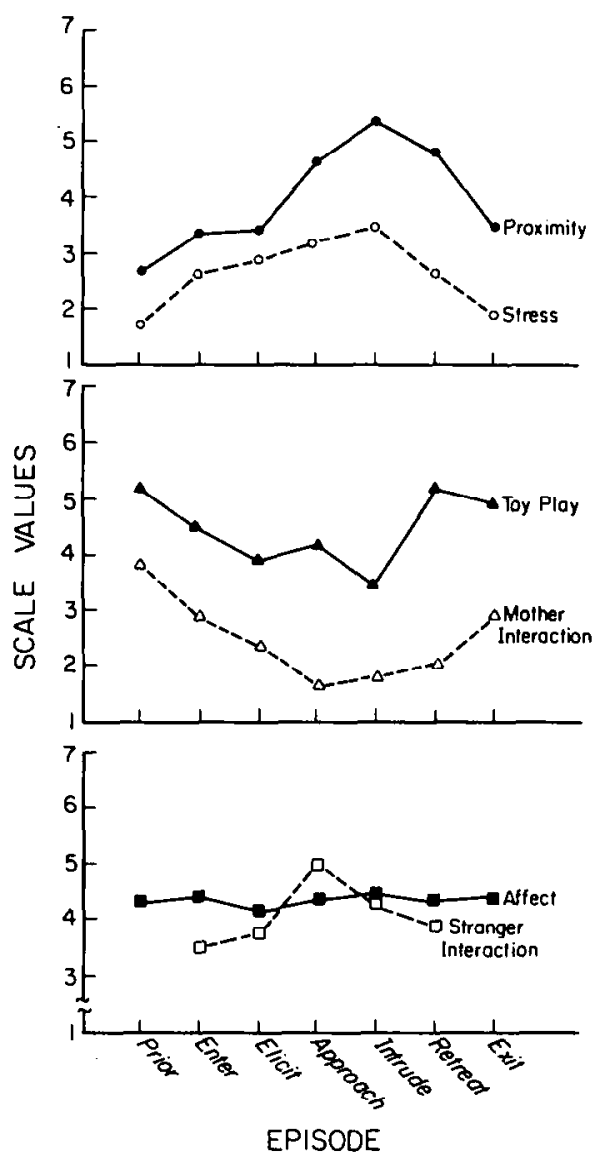

Flgure 1. Stranger-Sociability Scale Means.

overture in Episode 3. After that point, the children stayed consistently neutral, possibly reflecting vigilance and monitoring of the stranger's behavior.

Preterm Risk Status, Attachment, and Stranger Sociability

Before testing the three final hypotheses, possible interactions with sex of child were tested with three-way ANOVAs (Sex $\times$ Group $\times$ Episodes) with repeated measures for all three hypotheses. No significant interactions or main effects involving sex of child were found. Hence, sex of child was dropped from subsequent analyses.

Two steps were taken to test the hypotheses that differences in sociability ratings would be found between high-risk and low-risk infants, secure and insecure infants, and $A$ versus $C$ infants. The first step was designed to account for redundancy among the dependent measures through the use of a MANOVA with repeated measures for each hypothesis. In the MANOVAs, the seven epi- 
sodes constituted the repeated measure, hence limiting these analyses to 5 of the 6 scales because Stranger Interaction could not be scored in Episodes 1 and 7 when the stranger was absent. A separate ANOVA with repeated measures was conducted to test the hypotheses for Stranger Interaction. A multi-factor testing for interactions between the two risk groups and three attachment groups was not employed because of the limitations of cell size. The second step occurred if the overall Hotelling's $T$-square statistic was significant for the MANOVA, in which case the individual scales and their interactions with episode were examined.

The association of preterm risk status with sociability was tested first. The MANOVA with repeated measures for the five scales with seven episodes was not significant, $F(5,42)=1.12$, n.s. The ANOVA with repeated measures for the five-episode Stranger Interaction scale also did not approach significance, $F(1,46)=0.38$, n.s. Thus, this hypothesis received no support. By age 3, risk status does not appear to be strongly associated with different patterns of stranger sociability.

Next, the association of security of attachment (i.e., Secure vs. Insecure groups) with the Sociability variables was tested. The MANOVA with repeated measures for the five seven-episode scales was significant, $F(5,42)=2.71$, $p<.05$. Therefore, the individual scales and their interactions with episode were examined. Significant main effects for Toy Play, $F(1,46)=6.78, p<.05$, Affect, $F(1,46)=5.05, p<.05$, and Stress, $F(1,46)=10.48, p<.005$ were found. In addition, the ANOVA with repeated measures for Stranger Interaction was significant for the main effect, $F(1,46)=4.83, p<.05$. Only two scales-Proximity and Mother Interaction-did not show main effects. In all cases, the effects were in the predicted direction, with children from secure dyads showing more positive or optimal behaviors. Specifically, infants who were securely attached to their mothers in the second year of life had a more positive interaction with the stranger, were less stressed by the situation, had a more positive experience in the sociability procedure, and maintained a higher level of toy and imaginary play. In other words, as predicted, children who had earlier histories of secure attachment relationships demonstrated greater comfort, ease, and positive adaptation in the stranger-sociability situation.

An interaction of security of attachment with episode was observed. The MANOVA with repeated measures for the interaction of attachment and episode was significant, $F(30,1090)=1.45, p=.05$, with a significant interaction for Stress, $F(6,276)=2.26, p<.05$, and trends toward interaction for Mother Interaction, $F(6,276)=1.80, p<.10$, and Affect, $F(6,276)=2.26, p<.10$. In addition, the ANOVA with repeated measures for the interaction of attachment and episode on Stranger Interaction was significant, $F(6,41)=2.42, p<.05$. These interactions indicate that Secure/Insecure differences for these dimensions are dependent upon the particular situations implicit in the episodes. To help interpret these interactions, Table 4 presents comparisons of Secure/Insecure means by Episode. The overall pattern that emerges from these results 
TABLE 4

\begin{tabular}{ccccccccc}
\multicolumn{8}{c}{ Comparisons of Means of Secure (Sec) and Insecure (Insec) } \\
Stranger-Sociability Scales
\end{tabular}

Note. All tests are one-way ANOVAs $(d f=1,46)$.

${ }^{*} p<.10 ; \quad * * p<.05 ; \quad * * *<<.01 ; \quad * * * p<.005$.

can be summarized as follows: Strong and consistent differences between the secure and insecure groups were obtained when the situational stress increased due to the intrusion of the stranger into the child's personal space (Episodes 4 and 5). When this occurred, the secure children became more responsive to the stranger, showed increased positive affect, were less stressed, and had less need to interact with their mothers. Furthermore, as the situational demands decreased during the stranger-withdrawal phases (Episodes 6 and 7), the secure children showed greater independence and continuing interest in the stranger, maintained a higher level of positive affect, and generally returned to the low levels of stress seen prior to the stranger's entrance. Thus, the secure children displayed more positive responses and coping behavior during the most stressful episodes and more resilience during the final two recovery episodes than the insecure children.

The final hypothesis received no support. When the scores of the children with $\mathrm{A}$ attachment histories were compared to those with $\mathrm{C}$ attachment histories, the MANOVA was nonsignificant, $F(5,14)=1.00$, n.s., as was the ANOVA for Stranger Interaction scale, $F(1,18)=1.41$, n.s.). Although the differences between the $\mathrm{A}$ and $\mathrm{C}$ groups were in the predicted direction, the type of insecure attachment relationship bore no reliable relationship to how these children reacted during the stranger-sociability procedure.

\section{DISCUSSION}

This study demonstrated the existence of a strong relationship between attachment in the second year and sociability assessed at 36 months. These findings are consistent with those of others (Lutkenhaus et al., 1985) but go beyond 
previous investigations by examining child-stranger interactions in greater detail and in a more controlled setting than was previously accomplished, thus clarifying the relationship between children's behavior and differing levels of social demands on the part of the adult. Additionally, this study examined sociability among two groups of preterm infants that differed by severity of risk status.

As predicted by the first hypothesis, the behavior of the 3-year-olds in this study clearly shifted in accord with the pattern of the stranger's entry, approach, and withdrawal. This pattern of behavior underscores the importance of considering the degree of intrusion into the child's personal space when studying stranger sociability (Horner, 1983). Furthermore, this overall behavior pattern reflects the simultaneous arousal of interest and wariness in response to the approach of a stranger. Sroufe $(1977 ; 1979)$ suggested that the Strange Situation triggers these dual motivations of curiosity and wariness. As shown by this study, there is a mixture of interest about who the unfamiliar person is and what she is doing, combined with a wariness of the unfamiliar and uncertainty about the situation.

As predicted from the attachment literature, the secure children were more social and positive in interacting with an unfamiliar person. Securely attached children have experienced their caregivers as responsive, available, and sensitive, and have successfully used caregivers as a secure base for exploration and as a comfort when distressed. According to Sroufe and his colleagues (Matas et al., 1978; Sroufe, 1983; Sroufe, Fox, \& Pancake, 1983), there is continuity in the organization of this behavior across situations and over time. As they grow older, such children are able to continue to draw upon the security and consistency of the attachment relationship when they enter new situations. This facilitates their greater interest in the social environment and their ability to explore and enjoy new situations and interactions. Although attachment theorists predict that the internalized attachment relationship will become increasingly salient in organizing the preschool child's socioemotional adaptation (see Sroufe, 1983), this study cannot unequivocally support this position because children were assessed in the presence of their mothers. Nevertheless, these data clearly demonstrate the importance over time of the attachment relationship in providing a secure base for the young child's expanding adaptation to the social environment.

In contrast, the insecure group had not developed the same degree of trust and security in the caregiving relationship. Therefore, as predicted, the insecurely attached children were less sociable, less involved with the environment through play and interaction, and more stressed than the secure group. These results are consistent with other findings concerning quality of attachment and differences in social development (Frodi, 1983; Lutkenhaus et al., 1985; Main, 1983; Matas et al., 1978).

However, the hypothesis that there would be differences within the insecure group was not supported. Reliable differences between anxious-avoidant and 
anxious-resistant children were not found. The lack of significance in the $A$ versus $C$ findings may be due to small sample size and unstable variance. Although the differences between the resistant and avoidant groups were not significant, the patterns of behavior were in the predicted direction: The resistantly attached children were more stressed, less sociable, expressed less positive affect, and interacted more with their mothers than the avoidant group.

Also of importance was the absence of a strong relationship between risk status and sociability. Risk status did not prove to have a lasting effect that discriminated between the sociability behaviors of high-risk versus low-risk infants.

In short, the study has shown that young children's behavior in relationship to a stranger can be reliably assessed, and that, when accompanied by their mothers, the patterns of children's behavior in the presence of a stranger are significantly associated with their security of attachment as measured in the second year of life. Moreover, in this sample of children varying by degree of preterm postnatal risk, it is the quality of attachment-not the early risk status - that reliably predicts sociability with a stranger. The persistence of effects associated with the attachment relationship appears to signify that the quality of the infants' relationship with their primary caregivers during the first years of life appears to reduce the long-term impact of severe biological risk.

\section{REFERENCES}

Ainsworth, M.D.S., Blehar, M.C., Waters, E., \& Wall, S. (1978). Patterns of attactment: A fsichological study of the strange situation. Hillsdale, $\mathrm{NJ}$ : Erlbaum.

Brachfeld, S.. Goldberg. S.. \& Sloman, J. (1980). Parent-infant interaction in free play at 8 and 12 months: Effects of prematurity and immaturity. Infont Behovior and Development. 3 , 289-305.

Bretherton, I., \& Waters, E. (Eds.). (1985). Growing points of attachment theory and research. Monographs of the Society for Research in Child Development, 50(1-2, Serial No. 209).

Clarke-Stewart, A. (1978). Rezasting the lone stranger. In J. Glick \& A. Clarke-Stewart (Eds.), The development of social understanding. New York: Willey.

Crawford, J.W. (1982). Mother-infant interaction in premature and full-term infants. Child Development. 53. 957-962.

Crnic, K.A., Greenberg, M.T., Ragozin, A.S., Robinson, N.M.. \& Basham, R.B. (1983). Effects of stress and social support on mothers and premature and full-term infants. Child Development, 54, 209-217.

Divitto, B., \& Goldberg, S. (1979). The effetts of newborn medical status on early parent-infant interaction. In T.M. Field, A.M. Sostek, S. Goldoerg, \& H.H. Shuman (Eds.), Infants born at risk: Behavior and development. New York: Spectrum.

Field, T. (1977). Maternal stimulation during infant feeding. Developmental Psychologv, I3, $539-540$.

Frodi, A. (1983). Attachment behavior and sociability with strangers in premature and full-term infants. Infant Mental Hedth Journal. 4, 13-22.

Frodi, A., \& Thompson. R. (1985). Infant affective responses in the Strange Situation: Effects of prematurity and of quality of attachment. Child Development, 56, 1280-1290. 
Goldberg, S., Perrotta, M., Minde, K., \& Corter, C. (1986). Maternal behavior and attachment in low-birth-weight twins and singletons. Child Development, 57, 34-46.

Horner, T.M. (1983). On the formation of personal space and self-boundary structures in early human development: The case of infant-stranger reactivity. Developmental Review, 3, 148-177.

Lutkenhaus, P., Grossman, E.E., \& Grossman, K. (1985). Infant-mother attachment at twelve months and style of interactions with a stranger at the age of three years. Child Development, 56, 1538-1542.

Main, M. (1983). Exploration, play, and cognitive functioning related to infant-mother attachment. Infant Behavior and Development, 6, 157-174.

Matas, L., Arend, R.A., \& Sroufe, L.A. (1978). Continuity of adaptation in the second year: The relationship between quality of attachment and later competence. Child Development, 49, 547-556.

Meisels, S.J., Cross, D.R., \& Plunkett, J.W. (1987). Use of the Bayley Infant Behavior Record with preterm and full-term infants. Developmental Psychology, 23, 475-482.

Meisels, S.J., \& Plunkett, J.W. (in press). Developmental consequences of preterm birth: Are there long-term effects? In P.B. Baltes, D.L. Featherman, \& R.M. Lerner (Eds.), Life-span development and behavior (Vol. 9). Hillsdale, NJ: Erlbaum.

Minde, K., Whitelaw, A., Brown, J., \& Fitzhardinge, P. (1983). Effect of neonatal complications in premature infants on early parent-infant interactions. Developmental Medicine \& Child Neurology, 25, 763-777.

Plunkett, J.W, Meisels, S.J., Stiefel, G.S., Pasick, P.L., \& Roloff, D.W. (1986). Patterns of attachment among preterm infants of varying biological risk. Journal of the American Academy of Child Psychiatry, 25, 794-800.

Spitz, R. (1965). The first year of life. New York: International Universities Press.

Sroufe, L.A. (1977). Wariness of strangers and the study of infant development. Child Development, 48, 731-746.

Sroufe, L.A. (1979). Socioemotional development. In J.D. Osofsky (Ed.), Handbook of infant development. New York: Wiley.

Sroufe, L. (1983). Infant-caregiver attachment and patterns of adaptation in preschool: The roots of maladaptation and competence. In M. Perlmutter (Ed.), The Minnesora symposia on child psychology (Vol. 16). Hillsdale, NJ: Erlbaum.

Sroufe, L., Fox, E., \& Pancake, R. (1983). Attachment and dependency in developmental perspective. Child Development, 54, 1615-1627.

Stevenson, M.B., \& Lamb, M.E. (1979). Effects of infant sociability and the caretaking environment on infant cognitive performance. Child Development, 50, 340-349.

Stiefel, G.S., Plunkett, J.W., \& Meisels, S.J. (1987). Affective expression among preterm infants of varying levels of biological risk. Infont Behavior and Development, 10, 151-164.

Thompson, R., \& Lamb, M.E. (1982). Stranger sociability and its relationships to temperament and social experience during the second year. Infant Behavior and Development, 5. 277287.

Waters, E., \& Deane, K.E. (1985). Defining and assessing individual differences in attachment relationships: Q-methodology and the organization of behavior in infancy and early childhood. In I. Bretherton \& E. Waters (Eds.). Growing points of attachment theory and research. Monographs of the Society for Research in Child Development, $50(1-2$, Serial No. 209).

11 Moy 1987; Revised 23 November 1987 